Acta Theriologica 43 (1): 13-21, 1998.

PL ISSN 0001-7051

\title{
Testing energy expenditure hypotheses: reallocation versus increased demand in Microtus pennsylvanicus
}

\author{
Dominique BERTEAUX*
}

\begin{abstract}
Berteaux D. 1998. Testing energy expenditure hypotheses: reallocation versus increased demand in Microtus pennsylvanicus. Acta Theriologica 43: 13-21.

I tested the "reallocation" and "increased demand" hypotheses of seasonal allocation of energy using female meadow voles Microtus pennsylvanicus (Ord, 1815). I quantified the daily energy expenditure of adult females by the doubly labelled water method, both in the summer (reproductive) and winter (non-reproductive) seasons. Females were studied in field enclosures and were neither pregnant nor lactating, which made it possible to quantify the effect of season on non-reproductive costs. These costs were $20.6 \%$ higher in winter than in summer $\left(3.40\right.$ vs $2.82 \mathrm{~kJ} \times \mathrm{g}^{-1} \times$ day $^{-1}$ ). Laboratory data found in the literature showed that the cost of milk synthesis averages $3.53 \mathrm{~kJ} \times \mathrm{g}^{-1} \times \mathrm{day}^{-1}$. Assuming that these costs can be translated to natural conditions, daily energy expenditure of lactating females in the field is $225 \%$ that of non-reproductive ones. According to these results, females seem to follow a mixed strategy of both reallocation and increased demand of energy, although the observed pattern of allocation is much closer to an increased demand model. I discuss the assumption that lactation costs measured in captive voles can be transposed to field conditions, and propose an index of reallocation of energy that describes the strategy used by individuals. This index should permit the placement of each new species studied along the continuum of strategies that probably exists in mammals.
\end{abstract}

Département de Biologie, Université de Sherbrooke, Sherbrooke, Québec, Canada PQ J1K $2 \mathrm{R} 1$

Key words: Microtus pennsylvanicus, daily energy expenditure, reproductive strategy, seasonal energy allocation, voles

\section{Introduction}

Animals living in temperate or arctic climates generally breed only seasonally and synchronize the energy demanding phase of reproduction with spring or summer. Two hypotheses, originally formulated for birds (Masman et al. 1986, Weathers and Sullivan 1993) have been proposed to predict how individuals modify their allocation of energy according to annual changes in environmental conditions. The reallocation hypothesis predicts that there is little variation in total energy demand across seasons. It holds that abundant food and moderate temperatures

*Present address: Department of Biological Sciences, University of Alberta, Edmonton, Alberta, Canda T6G 2E9 


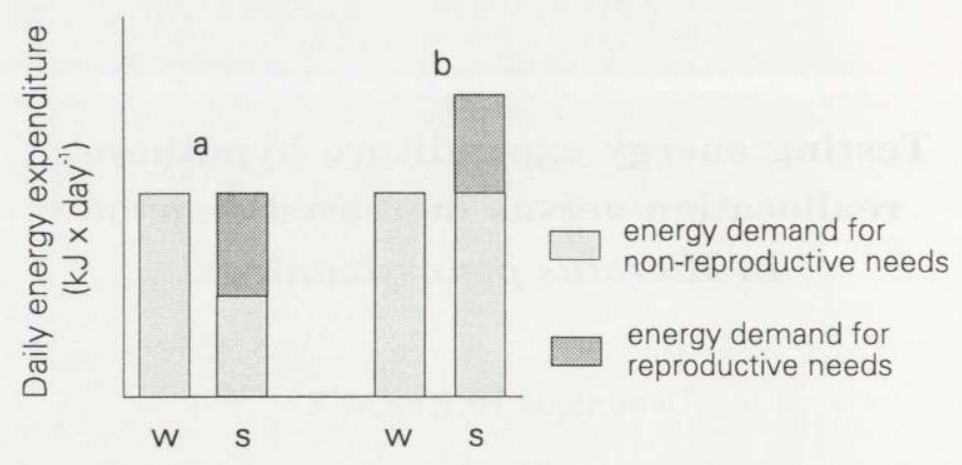

Fig. 1. Patterns of allocation of energy accross seasons as predicted by a pure strategy of reallocation of energy (a) and a pure strategy of increased demand of energy (b). w - winter, s - summer. No scale is provided on the $y$-axis because energy expenditure can vary widely from one species to the other.

during the breeding season result in decreased thermoregulatory and foraging costs, which allow energy to be reallocated to breeding. The increased demand hypothesis, on the other hand, predicts that total energy demand is maximal during the breeding season. It holds that reproduction involves sizeable energy requirements that can only be met during the period of maximal food availability (Fig. 1).

To date, some field tests of these hypotheses have been performed for bird species. Results are conflicting (Weathers and Sullivan 1993), suggesting that different models apply to different species. No general theory, however, allows us to understand why species should differ in their seasonal pattern of energy allocation. As far as mammals are concerned, seasonal patterns of energy allocation remain virtually unexplored in field conditions (Covell et al. 1996), except for some hibernating species that escape winter constraints by a reduced metabolism (Kenagy et al. 1989). In non-hibernators, which represent the great majority of mammals, there is no species for which we have data on both seasonal variations of energy expenditures of free-living individuals and reproductive costs in spring/summer (Nagy 1987, 1994). This lack of data prevents testing the predictive value of the 2 competing hypotheses.

Rodents of the genus Microtus are widely distributed mammals of small size that are active year-round, have high reproductive output, and are expected to face particularly high challenges in meeting their energy requirements (Wunder 1985). They are usually seasonal breeders that stop reproduction during the winter period. Here I present the results of an experiment where field energy expenditures of adult, non reproductive female meadow voles Microtus pennsylvanicus (Ord, 1815) were measured in both the summer (reproductive) and winter seasons. These results, combined with data on reproductive costs already present in the literature, allowed me to evaluate for the first time in a mammal species the predictive value of the competing hypotheses of reallocation and increased demand of energy. 


\section{Material and methods}

\section{Approach}

In mammals, females generally support most of the energetic costs of reproduction (Robbins 1993). I thus focus on this sex-class in all the study. The first requirement to test the hypotheses of reallocation and increased demand of energy is to quantify total energy expenditures of individuals across seasons. Then, one has to partition summer energy needs between reproductive and non-reproductive costs. Only such a partitioning indeed makes it possible to determine if there is a summer decrease in non-reproductive costs, which represents the potential for reallocating energy to breeding.

Measuring the cost of living in free-ranging animals is now routinely done by means of doubly labelled water (DLW). The energetic needs of reproducing female mammals, however, cannot be quantified solely by this method. Reproductive costs indeed include the mother's own oxidative metabolism devoted to reproduction (which can be measured by DLW), but also the amount of energy transferred to the young in milk as chemically bound energy (which cannot be measured by DLW) (Kenagy 1987). One alternative method is to compare the consumption of food by non-reproductive versus reproductive individuals. This, however, can only be achieved in the laboratory.

My approach consisted of measuring the cost of living (by means of DLW) of non-reproducing female meadow voles under field conditions, both in winter and summer. I then reviewed the literature for data on reproductive costs of $M$. pennsylvanicus and other species of microtines having similar body mass and litter size. These data were combined to my DLW results to evaluate total costs of living for females reproducing in the field in summer. Although differences may exist between the cost of reproduction in captivity and in the field, the approach presented here is the only one available given the field data that currently exist. I discuss later what potential biases this may introduce in the test of the two hypotheses.

\section{Measurement of non-reproductive costs across seasons}

Daily energy expenditures (DEE) were measured using doubly labelled water (DLW) in 35 adult female meadow voles maintained in outdoor enclosures. Living conditions in enclosures can be considered natural except that females did not have access to males. All individuals were thus non reproductive (neither pregnant nor lactating). Measurements of DEE were obtained for 24 individuals in winter and for 11 individuals in summer. My methods for studying voles in enclosures and determining energy demand of individuals have been detailed elsewhere (Berteaux et al. 1996a, c) and are only summarized here.

Individuals were born and raised in the laboratory (Berteaux et al. 1994). Animals were acclimatized to natural photoperiod and temperature before being introduced in 25 to $100 \mathrm{~m}^{2}$ outdoor enclosures. The acclimatization period lasted $11-18$ weeks for the winter experiment and $\geq 2$ weeks for the summer one. Pens were built in an oldfield community located on the campus grounds of the Université de Sherbrooke, Québec, Canada. The same enclosures were used in winter and summer, but animals were different. Voles were generally alone in enclosures, except in winter when some measurements were obtained on individuals living in groups of 4. Group living did not influence energy expenditures (Berteaux et al. 1996a), so data from the winter experiment were pooled irrespective of the social status of individuals. All the individuals studied in winter were radiocollared but this again did not influence energy demand (Berteaux et al. 1996b). After voles had spent 10-15 days in the enclosures for habituation, they were captured with Sherman traps and injected with DLW. After equilibration, a first blood sample was taken and animals were released in the enclosures. They were recaptured approximately 24 and/or 48 hours later to take second and/or third blood samples. This allowed the determination of DEE after analysis of blood samples using standard laboratory techniques (Nagy 1983). Winter measurements of DEE were performed during six 24-h periods occurring between January 25 and March 16, 1994. Summer measurements were performed during twelve 24-h periods from July 12 to August 22, 1994. The mean number of measurements 
obtained per individual was 1.5 in winter and 4.1 in summer. When several measures were obtained on the same individual, they were averaged to maintain independence of data. Ground temperatures (measured under the vegetation) ranged from -3.4 to $1.7^{\circ} \mathrm{C}\left(-1.3 \pm 1.4^{\circ} \mathrm{C}\right)$ during the 6 winter days of measurement and from 9.2 to $32.0^{\circ} \mathrm{C}\left(19.7 \pm 2.3^{\circ} \mathrm{C}\right)$ during the 12 summer days of measurement. Snow cover was permanent $(38 \pm 9 \mathrm{~cm})$ during the winter experiment.

\section{Energetic cost of reproduction}

The costs of reproduction of $M$. pennsylvanicus maintained in the laboratory have been published in one study (Innes and Millar 1981). Before relying on these unique results to estimate the total energy budget of reproducing female meadow voles in summer, however, I searched for similar studies performed on species having approximately identical life-history traits. These experiments were used as pseudo-replicates to gain confidence on the results obtained for $M$. pennsylvanicus. In total, data were obtained on 4 species of microtine rodents. In each laboratory experiment, the authors determined the difference between the amount of food consumed by reproductive versus non reproductive females. I determined the amount of energy actually used for reproduction by multiplying the quantity of energy consumed for reproductive needs by the assimilation efficiency of the food. Assimilation efficiencies were given by the authors in the studies of Kaczmarski (1966) and Migula (1969), whereas the assimilation efficiency of the rat chow used to feed animals in the study of Innes and Millar (1981) was considered to be $80 \%$ after Wunder (1985).

\section{Statistics}

Results are reported as means and standard deviations. All the tests used compare means and are two-tailed $t$-tests. Statistical significance was defined as $p<0.05$. Analyses were carried out with Statview for Macintosh (Abacus Concepts, Inc. 1987).

\section{Results}

Body mass of non-reproductive female meadow voles was not different according to season (Table 1). Daily energy expenditures of individuals, however, were significantly affected by season since winter needs were $20.6 \%$ higher than summer ones (3.40 vs $2.82 \mathrm{~kJ} \times \mathrm{g}^{-1} \times$ day $^{-1}$; Table 1$)$.

Table 1. Body mass and daily energy expenditure (DEE) of non breeding female meadow voles Microtus pennsylvanicus maintained in field conditions (large enclosures) in winter and summer, 1994. Data obtained by means of doubly labelled water. Sample size values apply to data on field metabolic rates.

\begin{tabular}{|c|c|c|c|c|c|}
\hline & \multicolumn{2}{|c|}{ Winter } & \multicolumn{2}{|c|}{ Summer } & \multirow{2}{*}{$\underset{(t \text {-test })}{p}$} \\
\hline & Min-max & Mean \pm SD & Min-max & Mean \pm SD & \\
\hline Body mass (g) & $27.5-40.7$ & $34.3 \pm 3.1$ & $30.4-40.8$ & $35.6 \pm 2.8$ & 0.262 \\
\hline $\begin{array}{l}\mathrm{DEE} \\
\mathrm{kJ} \times \mathrm{day}^{-1} \\
\mathrm{~kJ} \times \mathrm{g}^{-1} \times \mathrm{day}^{-1}\end{array}$ & $\begin{array}{l}97.0-176.3 \\
2.82-4.74\end{array}$ & $\begin{array}{r}116.5 \pm 17.5 \\
3.4 \pm 0.43\end{array}$ & $\begin{array}{l}64.0-115.6 \\
1.83-3.22\end{array}$ & $\begin{array}{r}100.4 \pm 17.6 \\
2.82 \pm 0.42\end{array}$ & $\begin{array}{l}<0.001 \\
<0.001\end{array}$ \\
\hline $\begin{array}{l}\text { Sample size } \\
\text { individuals } \\
\text { measurements }\end{array}$ & & $\begin{array}{l}24 \\
35\end{array}$ & & $\begin{array}{l}11 \\
45\end{array}$ & \\
\hline
\end{tabular}


Tabel 2. Energy used for reproduction, increased energy consumption during reproduction, and life-history traits related to reproduction in some female microtines of the genera Microtus and Clethrionomys. The species included in the table are those with similar litter size and body mass as $M$. pennsylvanicus. ${ }^{\mathrm{a}}$ body mass at mating, ${ }^{\mathrm{b}}$ body mass of non-reproducing females, ${ }^{\mathrm{c}}$ body mass post-partum, d data from Innes and Millar (1979).

\begin{tabular}{|c|c|c|c|c|c|c|c|}
\hline \multirow[t]{2}{*}{ Species } & \multirow[t]{2}{*}{$\begin{array}{l}\text { Body } \\
\text { mass } \\
(\mathrm{g})\end{array}$} & \multirow{2}{*}{$\begin{array}{l}\text { Litter } \\
\text { size } \\
\text { at } \\
\text { birth }\end{array}$} & \multirow{2}{*}{$\begin{array}{l}\text { Mass } \\
\text { at } \\
\text { birth } \\
\text { (g) }\end{array}$} & \multirow{2}{*}{$\begin{array}{c}\text { Mass at } \\
\text { weaning }(\mathrm{g}) \\
\text { (age in } \\
\text { days) }\end{array}$} & \multicolumn{2}{|c|}{$\begin{array}{l}\text { Energy used for reproduction } \\
{\left[\mathrm{kJ} \times(\mathrm{g} \times \text { day })^{-1}\right] \text { and increase }} \\
\text { over non-reproductives }(\%)\end{array}$} & \multirow[t]{2}{*}{ References } \\
\hline & & & & & Pregnancy & Lactation & \\
\hline C. glareolus & $25.0^{\mathrm{a}}$ & 5.0 & 1.6 & $9.0(18)$ & $0.69(24)$ & $2.69(92)$ & $\begin{array}{l}\text { Kaczmarski } \\
1966\end{array}$ \\
\hline M. arvalis & $25.3^{\mathrm{b}}$ & 4.2 & 1.7 & $7.8(16)$ & $0.56(32)$ & $2.51(133)$ & Migula 1969 \\
\hline C. gapperi & $26.8^{\mathrm{c}}$ & 5.6 & 1.7 & $9.2(14)^{d}$ & $1.37(68)$ & $3.41(144)$ & $\begin{array}{l}\text { Innes and } \\
\text { Millar } 1981\end{array}$ \\
\hline M. pennsylvanicus & $29.4^{\mathrm{d}}$ & 5.0 & 2.3 & $11.5(14)^{\mathrm{d}}$ & $0.85(36)$ & $3.53(123)$ & $\begin{array}{l}\text { Innes and } \\
\text { Millar } 1981\end{array}$ \\
\hline
\end{tabular}

Published measurements of reproductive costs for Microtus pennsylvanicus, M. arvalis, Clethrionomys glareolus, and C. gapperi are summarized in Table 2. Averaging values for these 4 microtine species shows that, in the laboratory, pregnant females need $40 \%$ more energy than non-reproductive ones, whereas lactation increases energy consumption by $123 \%$. These mean values are approximately those found in the only study on meadow voles (Innes and Millar 1981). The higher energy demand observed during lactation than during pregnancy is not surprising and has long been recognized in mammals (Brody 1945, Robbins 1993). I thus focus on the most energy demanding phase of reproduction, the lactation period, to compare the 2 hypotheses of energy allocation. From Innes

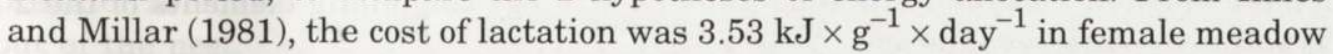
voles (mean cost during the whole lactation period). Assuming that such energy expenses can be translated to field conditions, the addition of this cost to the values of DEE observed in my study gives an estimate of $6.35 \mathrm{~kJ} \times \mathrm{g}^{-1} \times$ day $^{-1}$ for total energy expenditure of lactating females in the field.

\section{Discussion}

The DEE of meadow voles were high compared to those expected for a rodent of similar size, ranging from $156 \%$ of the predicted rate during summer, to $184 \%$ of the predicted rate during winter (expected rates calculated from equation 4 in Nagy 1987). The high DEE of $M$. pennsylvanicus may be related to their high basal metabolic rate (BMR), which has been measured to be 1.93 and $1.79 \mathrm{ml} \mathrm{O}$ $\times \mathrm{g}^{-1} \times \mathrm{h}^{-1}$ by Bradley (1976) and Thomas et al. (1988), respectively. If we take 
the mean of these two measures, BMR is $140 \%$ the value expected for a similar-sized eutherian mammal (Kleiber 1961). If we assume an energy equivalence of $20.1 \mathrm{~J} \times\left(\mathrm{ml} \mathrm{O}_{2}\right)^{-1}$ (Nagy 1983), the ratio of DEE to BMR of meadow voles is thus 3.80 in winter and 3.15 in summer. These values are well in the range of what is observed in other small eutherians (Koteja 1991, Degen and Kam 1995), indicating that although DEE is high in meadow voles, the relative energetic cost of living in excess of BMR does not seem to be particularly unusual.

Winter DEE, when expressed as a multiple of summer DEE, averaged 1.21. Covell et al. (1996) reviewed the literature for comparisons of DEE in summer and winter in non-reproductive eutherian mammals. They found that the mean multiple was $1.14 \pm 0.12(n=11)$, indicating that between-season differences in this study are not particularly high or low. The estimate of $6.35 \mathrm{~kJ} \times \mathrm{g}^{-1} \times$ day $^{-1}$ for total energy expenditure of lactating females in the field represents 5.7 times BMR. Again, this estimate lies very close to that observed for an other small rodent, the golden-mantled ground squirrel (Kenagy et al. 1990). This is approximately $146 \%$ the maximal rate of metabolizable energy intake $\left(4.36 \mathrm{KJ} \times \mathrm{g}^{-1} \times \mathrm{day}^{-1}\right)$ predicted by Kirkwood's (1983) equation.

The reallocation hypothesis predicts that non-reproductive costs are lower in the summer season, which is consistent with my observations. It also predicts that total energy expenditures of mature individuals are roughly the same in the non-reproductive, winter period, and in the reproductive, summer season. This is not supported by my estimates since energy expenditures of reproductive females in summer appeared much higher than those of non-reproductive females in winter. The increased demand hypothesis predicts highest energy expenditures during the reproductive season, which is in agreement with my calculations. Females, however, apparently had the opportunity to reallocate to reproductive needs the energy saved during the summer season, since non-reproductive needs in summer were lower than in winter. The strategy of energy allocation used by female meadow voles may thus be a mixed strategy combining elements of the 2 hypotheses under evaluation.

To my knowledge, no data is available to enable a comparison between the estimated energy allocation for meadow voles and that of other non-hibernating mammals. The important questions for future investigations, thus, should be: (1) to what extent does species i have the opportunity to reallocate some energy to reproductive needs during the spring/summer season? (2) are there between-species differences in the pattern of seasonal allocation of energy? and (3) if such differences exist, what are their proximate and ultimate causes? In order to answer these questions, we need a tool for comparing the strategies of different species. Hereafter I describe a simple index of reallocation of energy (IRE) that should make it possible to place each new species studied along a continuum of strategies. This index is calculated as:

$$
\mathrm{IRE}=\left(\mathrm{DEE}_{\mathrm{w}}-\mathrm{DEE}_{\mathrm{s}}\right) / \mathrm{DEE}_{\mathrm{r}}
$$


where: IRE - index of reallocation of energy, $\mathrm{DEE}_{\mathrm{w}}$ - daily energy expenditure during the non-reproductive season (winter), $\mathrm{DEE}_{\mathrm{s}}$ - daily energy expenditure associated with non-reproductive costs during the reproductive season (summer), and $\mathrm{DEE}_{\mathrm{r}}$ - daily energy expenditure for reproduction in summer (mainly energy involved in milk production and energy exported in milk as chemically bound energy).

The basic properties of this index are that it equals 1 for species that follow a strict reallocation model, whereas it equals 0 for species following a pure strategy of increased demand of energy. The index ranges from 0 to 1 for all other species following a mixed strategy of allocation of energy, but is negative for hibernators and non-hibernating species for which daily energy expenditure in winter is lower than non-reproductive costs in summer (see Covell et al. 1996 for some known examples). Finally, IRE may be $>1$ for species in which females spend more energy during the winter season than during the lactating period (no example to my knowledge).

As far as female meadow voles are concerned, results presented in this study show that $\mathrm{DEE}_{\mathrm{w}}=3.40{\mathrm{~kJ} \times \mathrm{g}^{-1} \times \text { day }^{-1} \text {, and suggest that } \mathrm{DEE}}_{\mathrm{s}}=2.82 \mathrm{~kJ} \times \mathrm{g}^{-1}$

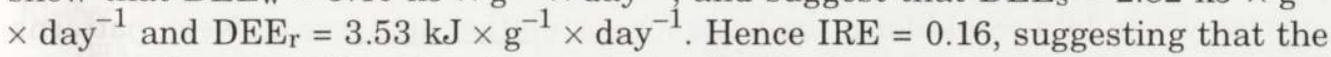
pattern of energy allocation in meadow voles is close to a strategy of increased demand of energy (IRE $=0$ ), although individuals can also rely in part on the reallocation of energy to satisfy the needs of reproduction.

The above conclusion is based on the assumption that total costs of breeding females are equivalent to the sum of lactation costs and DEE of non-lactating females. How realistic is this assumption? First, lactation costs may be higher in the field than in the laboratory. In captivity, lactating females can easily increase their food consumption without any additional foraging cost, whereas activity of voles in the field may dramatically increase when the needs for high quality food are boosted during milk synthesis. Increased activity may in turn augment predator avoidance costs or thermoregulation needs if more time has to be spent out of the nest. Ostfeld et al. (1988) measured the territory size of lactating and non lactating female meadow voles. They did not detect any difference between the two groups, suggesting that females do not extend their range further from the nest when lactating. To my knowledge, no other evidence exist to either support or reject the potential biases mentioned above. It is important to note, however, that any additional cost of lactation would reinforce rather than weaken my conclusions (ie would decrease IRE).

Second, non reproductive costs of lactating voles in the field may be lower than DEE of non breeding females. This may be the case if non breeding females spend some energy on male searching, or if lactating females substitute costs, for example heat produced from activity aiding thermoregulation. To what extent could these processes have led to an underestimation of IRE? It is unlikely that searching for males was an important cost for non reproductive females in my study. Measured DEE were indeed similar to those of non breeding females and males maintained 
in small cages during an other study (Berteaux et al. 1996a), during which activity of individuals did not seem to be particularly important. The magnitude to which substitution of costs may have decreased energy expenses of lactating females is less clear. A simple reasoning, however, shows that minimum energy expenditure of lactating females in the field is $5.11 \mathrm{~kJ}^{-1} \mathrm{~g}^{-1} \times$ day $^{-1}$, the DEE of lactating females maintained in cages at $20^{\circ} \mathrm{C}$ (Innes and Millar 1981). Similarly, the minimal non reproductive cost of living in the field is $1.58 \mathrm{~kJ}^{\circ} \mathrm{g}^{-1} \times \mathrm{day}^{-1}$ (the value measured in the laboratory for non-lactating females; Innes and Millar 1981). Hence, given that the cost of living in winter is $3.40 \mathrm{~kJ} \mathrm{~g} \mathrm{~g}^{-1} \times \mathrm{day}^{-1}$, the maximal value IRE could take is 0.37 , which is still far from a strategy of increased demand.

In conclusion, female meadow voles seem to follow a mixed strategy of both reallocation and increased demand of energy, although the observed pattern of allocation is much closer to an increased demand model. Results from this study may not be definitive because they rely in part on laboratory data, but they do offer a clear and quantitative prediction for future research. Furthermore, they provide a valuable stimulus to quantify the index of reallocation of energy in other species. Such data would form the basis for correlation analyses between patterns of seasonal allocation of energy of different species and their life-history traits or the characteristics of their environment. There probably lies the foundation for exploring the evolutionary origins of the various strategies of energy allocation mammals use in the field.

Acknowledgements: I thank P. Albert, J. Bêty, A. Frève, F. Masseboeuf and E. Rengifo for field assistance, P. Albert, J. Bêty and M. Léonard for assistance in analysis of blood samples, B. Mercier and D. Proulx for animal care, and D. Thomas for comments on the manuscript. Funds for this study were provided by the Natural Sciences and Engineering Research Council of Canada and the Fondation pour la Formation de Chercheurs et l'Aide à la Recherche of Québec through research grants to J-M. Bergeron and D. Thomas. This is publication 110 of the Groupe de Recherche en Ecologie, Nutrition et Énergétique, Université de Sherbrooke.

\section{References}

Abacus Concepts, Inc. 1987. Statview II. Abacus Concepts, Inc., Berkeley

Berteaux D., Duhamel R. and Bergeron. J-M. 1994. Can radio collars affect dominance relationships in Microtus? Canadian Journal of Zoology 72: 785-789.

Berteaux D., Bergeron J-M., Thomas D. W. and Lapierre H. 1996a. Solitude versus gregariousness: do physical benefits drive the choice in overwintering meadow voles? Oikos 70: 330-336.

Berteaux D., Masseboeuf F., Bonzom J-M., Bergeron J-M., Thomas D. W. and Lapierre H. 1996b. Effect of carrying a radiocollar on expenditure of energy by meadow voles. Journal of Mammalogy 77: $359-363$.

Berteaux D., Thomas D. W., Bergeron J-M. and Lapierre H. 1996c. Repeatability of daily field metabolic rate in female meadow voles (Microtus pennsylvanicus). Functional Ecology 10 751-759.

Bradley S. R. 1976. Temperature regulation and bioenergetics of some microtine rodents. $\mathrm{Ph} \mathrm{D}$ thesis, University of Cornell, Ithaca, New York: 1-145.

Brody S. 1945. Bioenergetics and growth. Reinhold Publication Corporation, New York: 1-1023. 
Covell D. F., Miller D. S. and Karasov W. H. 1996. Cost of locomotion and daily energy expenditure by free-living swift foxes (Vulpes velox): a seasonal comparison. Canadian Journal of Zoology 74: 283-290.

Degen A. A. and Kam M. 1995. Scaling of field metabolic rate to basal metabolic rate ratio in homeotherms. Écoscience 2: 48-54.

Innes D. G. L. and Millar J. S. 1979. Growth of Clethrionomys gapperi and Microtus pennsylvanicus in captivity. Growth 43: 208-217.

Innes D. G. L. and Millar J. S. 1981. Body weight, litter size, and energetics of reproduction in Clethrionomys gapperi and Microtus pennsylvanicus. Canadian Jopurnal of Zoology 59: 785-789.

Kaczmarski F. 1966. Bioenergetics of pregnancy and lactation in the Bank vole. Acta Theriologica 19: 409-417.

Kenagy G. J. 1987. Energy allocation for reproduction in the golden-mantled ground squirrel. Symposia of the Zoological Society of London 57: 259-273.

Kenagy G. J., Sharbaugh S. M. and Nagy K. A. 1989. Annual cycle of energy and time expenditure in a golden-mantled ground squirrel population. Oecologia 78: 269-282.

Kenagy G. J., Masman D., Sharbaugh S. M. and Nagy K. A. 1990. Energy expenditure during lactation in relation to litter size in free-living golden-mantled ground squirrels. Journal of Animal Ecology 59: 73-88.

Kirkwood J. K. 1983. A limit to metabolisable energy intake in mammals and birds. Comparative Biochemistry and Physiology 75A: 1-3.

Kleiber M. 1961. The fire of life: an introduction to animal energetics. John Wiley and Sons, New York: $1-454$

Koteja P. 1991. On the relation between basal and field metabolic rates in birds and mammals. Functional Ecology 5: 56-64.

Masman D., Gordijn M., Daan S. and Dijkstra C. 1986. Ecological energetics of the kestrel: field estimates of energy intake throughout the year. Ardea 74: 24-39.

Migula P. 1969. Bioenergetics of pregnancy and lactation in european common vole. Acta Theriologica 13: $167-179$.

Nagy K. A. 1983. The doubly labeled water $\left({ }^{3} \mathrm{HH}^{18} \mathrm{O}\right)$ method: a guide to its use. University of California, Los Angeles Publication, 12-1417: 1-45.

Nagy K. A. 1987. Field metabolic rate and food requirement scaling in mammals and birds. Ecological Monograph 57: 111-128.

Nagy K. A. 1994. Field bioenergetics of mammals: what determines field metabolic rates? Australian Journal of Zoology 42: 43-53.

Ostfeld R. S., Pugh S. R., Seamon J. O. and Tamarin R. H. 1988. Space use and reproductive success in a population of meadow voles. Journal of Animal Ecology 57: 385-394.

Robbins C. T. 1993. Wildlife feeding and nutrition: second edition. Academic Press, San Diego: 1-352.

Thomas D. W., Samson C. and Bergeron J-M. 1988. Metabolic costs associated with the ingestion of plant phenolics by Microtus pennsylvanicus. Journal of Mammalogy 69: 512-515.

Weathers W. W. and Sullivan K. A. 1993. Seasonal patterns of time and energy allocation by birds. Physiological Zoology 66: 511-536.

Wunder B. A. 1985. Energetics and thermoregulation. [In: Biology of new world Microtus. R. H. Tamarin, ed]. American Society of Mammalogists Special Publication 8: 812-844. 